\title{
RECRUITMENT, DIET COMPOSITION, AND TIME-BUDGETS OF BIGHORN SHEEP (OVIS CANADENSIS) IN THE TETON RANGE
}

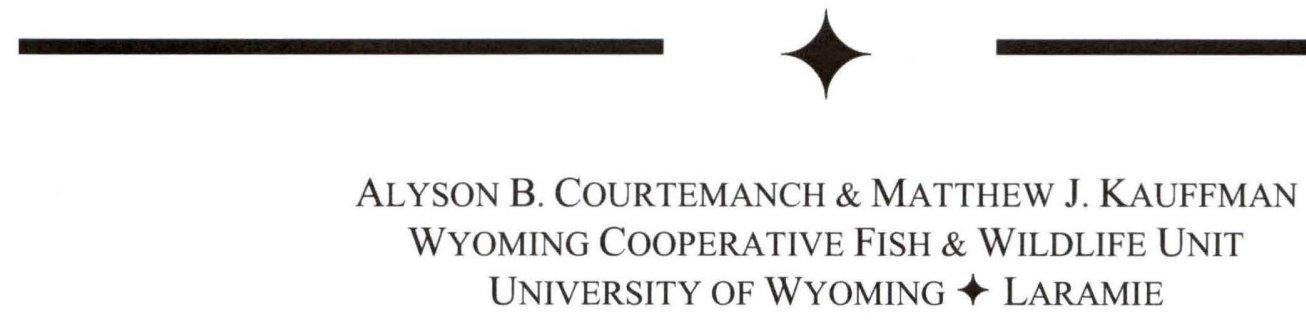

\section{$\uparrow \quad$ Abstract}

Many ungulate populations have lost access to their traditional migration routes and seasonal ranges, resulting in rapid and severe population declines. Some ungulate populations have been able to adapt to living year-round on one seasonal range and persist despite loss of migration. However, our understanding of how ungulates adapt their habitat selection and foraging strategies in order to compensate for migration loss is poor. This study investigates how a formerly migratory, now sedentary and isolated bighorn sheep (Ovis canadensis) population persists year-round on high-elevation summer range in the Teton Range in northwest Wyoming. We captured and GPS-collared 20 bighorn ewes throughout the Teton Range in February 2008 and an additional 8 ewes in March 2009. In 2008 , ninety percent of captured ewes were pregnant, and $100 \%$ were pregnant in 2009. During summer 2008, we located and observed GPS-collared ewes, determined lamb survival, collected fecal samples for diet composition analysis, and observed time-budgets. We found that $50 \%$ of lambs survived until at least midsummer. Diet composition analysis is pending and we are waiting to combine time-budget observations with additional data that will be collected during summers 2009 and 2010. We observed differences in movement patterns between GPS-collared ewes during summer 2008, ranging from $5 \mathrm{~km}$ to a maximum of $15 \mathrm{~km}$. At this time, six GPS-collared ewes have died (four in avalanches, one from predation, and one unknown). This study is ongoing and will be completed in 2010 . Results will directly contribute to management of this non-migratory and isolated bighorn sheep population, and will shed light on how a formerly migratory ungulate population has been able to persist on highelevation range year-round.

\section{$\downarrow \quad$ INTRODUCTION}

Animal migration is one of the most spectacular natural phenomena on the planet. Despite its inherent appeal to the human imagination, we are only beginning to understand the connections between migration, ungulate population dynamics, and the ecological consequences of migration disruption and loss (Bolger et al. 2008). Over the past two centuries, ungulate migrations around the world have been threatened due to human activities, commonly in the form of anthropogenic barriers or land conversion and habitat loss (Bolger et al. 2008). Where migration routes have been disrupted or lost, the result is often rapid population decline and at the extreme, local extinction (Newmark 1996, Mwangi 1998, Bolger et al. 2008). For example, between the late 1970 s and 1990 s, there was an $81 \%$ decline in the wildebeest (Connochaetes taurinus) population in the Masai Mara ecosystem in southern Kenya attributed to conversion of wet season calving and breeding range to agricultural uses (Ottichilo et al. 2001, Serneels \& Lambin 2001).

Loss of access to winter, dry season, or breeding ranges appears to reduce carrying capacity, although the exact nature of the mechanisms and effects on ungulate populations is unclear (Bolger et al. 2008). While some ungulate populations experience a severe 
decline and local extinction after the loss of traditional migration routes, some populations continue to persist, although with lower numbers (Whitfield 1983). In such cases, it is unknown how ungulate populations behaviorally adapt to living year-round on one seasonal range. Our current understanding of ungulate migration losses begs the following questions: How do their habitat selection strategies change in order to survive in a sub-optimal habitat for at least part of the year? What novel pressures do sedentary, non-migratory ungulates face and how do they cope with them? Which species and ecosystems are best able to persist after migration routes have been lost?

Due to their specialized habitat requirements (i.e. proximity to escape terrain, good horizontal visibility) bighorn sheep (Ovis canadensis) have a naturally fragmented distribution, with habitat patches connected by traditional non-habitat movement corridors (Risenhoover 1988, Bleich et al. 1990, Valdez \& Krausman 1999). This naturally fragmented distribution was exacerbated by the arrival of EuroAmericans to the West in the late 1800 s, which caused a catastrophic decline of bighorn sheep numbers due to the combined effects of disease (primarily scabies caused by the Psoroptes mite), overhunting, competition for forage with domestic livestock, and displacement from winter range (Buechner 1960). This decline resulted in many small, isolated populations and loss of traditional migration corridors (Risenhoover 1988). More recent habitat losses from agricultural, industrial, and recreational development, fire suppression, and anthropogenic barriers to movement such as roads and fences have led to further disruption of historic bighorn sheep migrations and interpopulation connectivity. Because bighorn sheep are poor colonizers of new habitats (Risenhoover et al. 1988), they are particularly vulnerable to population decline and local extirpation from loss of traditional migration routes and seasonal range reduction from anthropogenic influences.

Like many ungulates, most bighorn sheep populations undertake seasonal altitudinal migrations (Shackleton et al. 1999). Seasonal altitudinal movements allow bighorn sheep to access the highest quality and most digestible forage available within their home range. Bighorn sheep are able to take advantage of low elevation vegetation growth in spring and follow new growth to higher elevations, accessing nutritious forage into mid and late summer (Klein 1965). Hebert (1973) concluded that altitudinal migration was essential to maintaining seasonal bighorn sheep nutrition.
The Teton Range bighorn sheep herd in northwest Wyoming is an example of a sheep population that has abandoned its historic migration to low-elevation winter range. Prior to the arrival of EuroAmerican settlers to Jackson Hole and Teton Valley in the late 1800 s, bighorn sheep wintered in the foothills and valleys surrounding the Teton Range. However, due to a number of factors including human development, widespread domestic sheep grazing, fire suppression, and construction of roads and fences, bighorn sheep abandoned their historic migration routes and by the mid-1900s became a non-migratory, isolated population summering and wintering at high elevations in the Teton Range (Whitfield 1983). Nevertheless, the herd continues to persist and provides us an opportunity to investigate an ungulate population's ability to adapt to migration loss.

The main objectives of this study are to 1) compare bighorn sheep habitat selection during summer and winter, and 2) evaluate bighorn sheep avoidance of suitable winter habitats where human recreation occurs. These objectives will be addressed mainly with data from GPS-collars and winter field work. However, we are also gathering supplemental information during summer seasons about relatively unknown vital rates for this population (i.e. adult mortality and lamb survival), diet composition, and time-budgets (time spent foraging vs. time spent vigilant for predators) to compare with data from migratory sheep populations. We hypothesize that in order for this non-migratory population to persist year-round on high elevation summer range, they may exhibit different foraging strategies and anti-predator behaviors than migratory sheep populations in similar habitats.

\section{STUDY AREA}

The Teton Range bighorn sheep herd resides year-round at high elevations in Grand Teton National Park (GTNP), Bridger-Teton National Forest (BTNF), and Caribou-Targhee National Forest (CTNF) (Fig. 1). The Teton herd is Wyoming's smallest and most isolated native herd - a remnant population of perhaps 125-150 sheep derived from a much larger bighorn sheep complex that historically occupied northwest Wyoming. Unlike many other bighorn sheep herds in the Rocky Mountain West, the Teton herd has yet to experience a transplant to augment population size (Hurley 1996).

Growing recognition of the tenuous status of the Teton bighorn sheep population and the need for interagency cooperation in managing the herd led to the formation of the Teton Range Bighorn Sheep Working 
Group (TRBSWG) in 1990. This group identified a number of threats to the herd's future persistence including small population size, genetic isolation from surrounding herds, limited and poor quality winter range, and disturbance from increasing levels of winter backcountry recreation (Teton Range Bighorn Sheep Working Group 1996). Wildlife biologists and managers in the area are striving to develop effective strategies to manage this herd without having to augment numbers with a transplant.

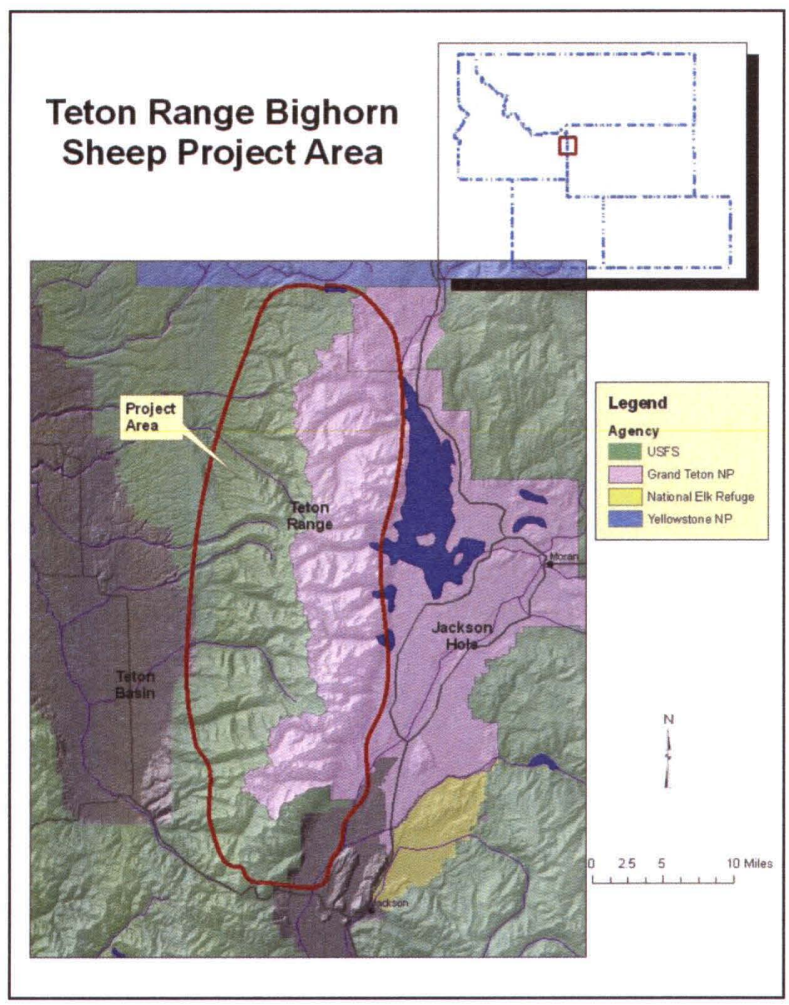

Figure 1. Project study area.

\section{$\downarrow \quad$ METHODS}

\section{Capture and GPS-collaring}

To evaluate bighorn sheep seasonal habitat selection, Telonics GPS store-on-board collars (Telonics, Inc., Mesa, Arizona, U.S.A.) were deployed on 20 ewes in February 2008. Ewes were captured by net-gunning from a helicopter (Leading Edge Aviation, Lewiston, Idaho) throughout the Teton Range (Fig. 2). The GPS collars are programmed to collect a GPS fix every five hours during the winter (15 November - 15 April) and summer (15 June - 15 September) and every 25 hours during the fall (16 September -14 November) and spring (16 April- 14 June). The collars are programmed to drop off on 15 July 2010, yielding about $2 \frac{1}{2}$ years of data. During captures, blood $(20 \mathrm{cc})$ was collected from all ewes for pregnancy and disease analysis, and ear swabs for mite testing. Fecal, tissue, and an additional blood sample were collected from all ewes for contribution to a genetic study being conducted by Grand Teton National Park. In addition, we estimated age with horn ring counts, and we recorded capture and release times.

In March 2009, we captured and GPS-collared an additional eight bighorn ewes, implementing the same capture techniques as in the previous year (Fig. 2). We collected the same biological samples for pregnancy, disease, and genetic testing, recorded horn rings, capture and release times, and weighed individuals.

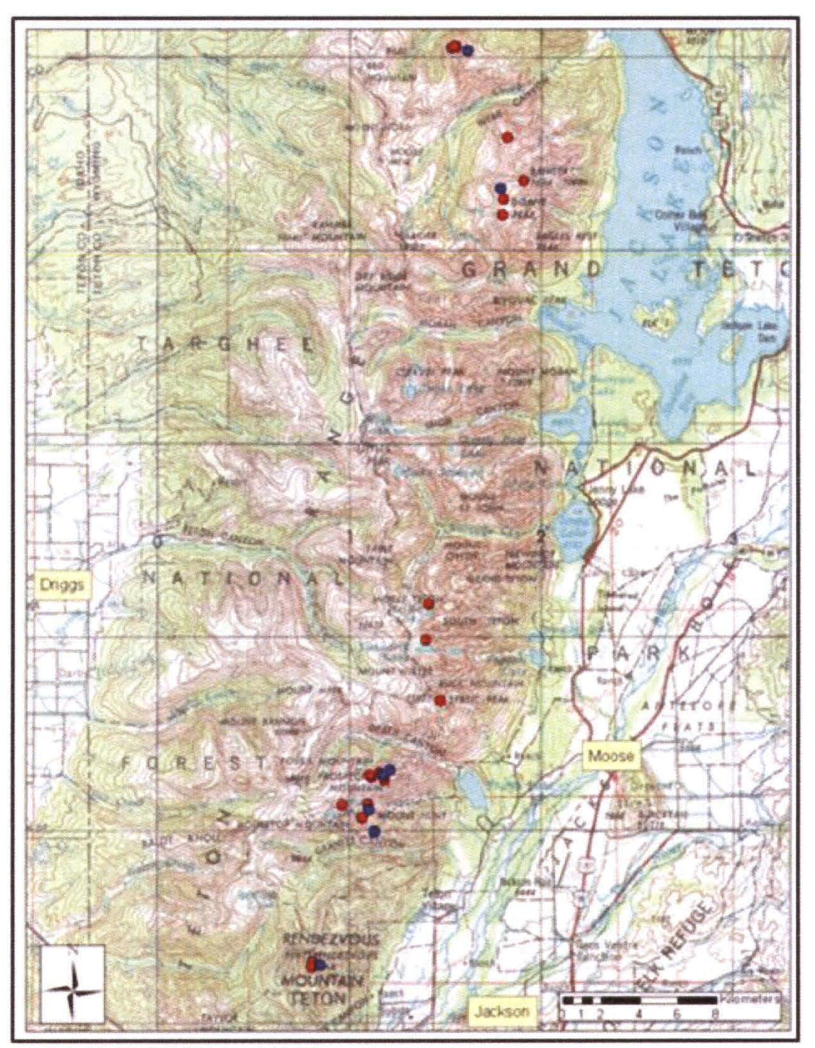

Figure 2. Bighorn sheep capture locations in the Teton Range, February 2008 (red) and March 2009 (blue).

\section{Monitoring adult mortality}

In order to monitor for GPS-collared sheep mortalities and obtain general locations of sheep throughout the study period, monthly telemetry flights were conducted with a fixed-wing aircraft (Sky Aviation, Driggs, Idaho). These flights were increased to two times per month during the summer season (June - August) to assist field crews in locating GPS-collared sheep from the ground. Mortalities were investigated as soon as possible on the ground, and standard necropsy procedures were conducted. 


\section{Summer field data collection}

During summer 2008, we collected field data to enhance our understanding of Teton Range bighorn sheep demography, diet, and behavior. After the completion of data collection in summers 2009 and 2010, we will compare the diet composition, behavior, and lamb survival of the non-migratory Teton bighorn sheep population with findings from studies of migratory sheep populations in similar habitats.

\section{Lamb survival}

During summer 2008, two field crews made up of two people each monitored lamb survival for GPScollared ewes from June to August. Field crews spent 4-5 days in the backcountry at a time, and located and observed each GPS-collared ewe at least four times to determine the presence or absence of a lamb. We identified lamb/ewe pairs by observing suckling behavior. In bighorn sheep, it is rare for a ewe to allow a lamb other than her own to suckle (Valdez \& Krausman 1999). In addition to lamb survival, we also recorded bighorn sheep group sizes and composition.

\section{Diet composition}

We collected bighorn sheep fecal samples from June to August 2008 for diet composition analysis at the Washington State University Wildlife Habitat and Nutrition Laboratory in Pullman, Washington. Fresh samples were combined into three composite samples to represent bighorn sheep diets in June, July, and August 2008. Major forage plants ( $>5 \%$ of diet) and the percent content of forage classes (grass, shrub, forbs, etc.) were identified. Because it was difficult and timeconsuming to collect fresh fecal samples, we also opportunistically collected older fecal samples that we came across in the field. These samples were combined into composite samples for the northern (areas north of Mount Moran) and southern (areas south of the Middle Teton) herd segments in the Teton Range. These composite samples were analyzed for percent content of forage classes only. These data will be compared to other bighorn sheep foraging studies to determine whether this herd selects summer forage differently than migratory sheep herds.

\section{Sheep foraging and time-budgets}

Non-migratory and migratory ungulates may exhibit different seasonal patterns of foraging and vigilance behaviors. Non-migratory bighorn sheep that winter at high elevations may have to spend more time foraging and less time being vigilant during the summer in order to gain enough fat stores to survive on relatively marginal forage during the winter. Bighorn sheep in the Tetons may be forced to rely more heavily on their fat reserves during winter than migratory populations. During summer 2008, field crews located groups of bighorn sheep and conducted time-budget observations to determine percent of time spent foraging vs. percent of time spent vigilant. After locating a group, we observed each individual in the group for 15 minutes, and calculated the proportion of time spent foraging, vigilant, moving, standing, and bedded. In addition, a group scan was conducted every 5 minutes during each 15 -minute observation period and behaviors were recorded for all individuals in the group. For each focal individual, we recorded sex, approximate age, and presence of lamb, as well as group size, composition, and estimated distance from escape terrain, all of which have been demonstrated to influence anti-predator behavior in ungulates (Berger 1978, Frid 1997, Lung \& Childress 2006).

\section{RESULTS \& DISCUSSION}

\section{Captures}

The average estimated age of captured ewes was 4.35 years $(\min =1$ year, $\max =8$ years $)$ in 2008 and 3.25 years $(\min =2$ years, $\max =4$ years $)$ in 2009 . The average weight of ewes in 2009 was $59 \mathrm{~kg}$ ( $\mathrm{min}=$ $50 \mathrm{~kg}, \max =66 \mathrm{~kg}$ ). Average processing time for captured ewes in 2008 was 10 minutes $(\min =5$ minutes, $\max =13$ minutes $)$, and 16.5 minutes $(\min =9$ minutes, $\max =28$ minutes) in 2009. The increase in 2009 was due to extra time needed for weighing individuals.

\section{Pregnancy and disease testing}

Pregnancy testing revealed that 17 of 19 ewes of reproductive age $(90 \%)$ were pregnant in 2008 . In $2009,100 \%$ of ewes were pregnant. These rates of pregancy suggest that conditions on high-elevation range are not severe enough to impact pregnancy rates in late-winter.

In 2008 and 2009, captured ewes tested negative or had extremely low titers for 12 common bighorn sheep diseases: caprine arthritis encephalitis, ovine progressive pleuropneumonia, infectious bovine rhinotracheitis, bovine viral diarrhea, parainfluenza virus, respiratory synctial virus, bluetongue, Johne's disease, Brucella ovis, wildlife brucellosis serology, epizootic hemorrhagic disease virus, and Psoroptes mites. These results indicate very low previous disease exposure for this isolated population. Of special note are the low titers results for parainfluenza virus, to which nearly $100 \%$ of Wyoming ungulates have been exposed (H. Edwards, pers. comm.). For the time being, these results are reassuring because they do not 
indicate any immediate disease threat to the Teton herd. However, the low titers suggest that this population is naïve to many diseases, which may increase the risk of population decline if a new disease infects the herd in the future. Also, the tradeoff of benefits and risks of a potential transplant will have to be seriously considered by wildlife biologist and managers. The risk of introduction of disease into the Teton herd through a transplant may outweigh the benefit of increasing population numbers and genetic diversity.

\section{Adult mortality and lamb survival}

Five $(25 \%)$ GPS-collared ewes died during the first year of the study (2008). Three were killed in spring avalanches, one died from unknown causes in the fall, and one died in a winter avalanche (Fig. 3). We have had one mortality so far in 2009 ; one of the newly captured ewes died in mid-April from apparent predation (likely a mountain lion). This preliminary mortality rate for adult females appears high especially for a relatively small population. Combined mortality data from the entire study (2008 -2010) will allow a more accurate estimate of adult ewe mortality

We observed each GPS-collared ewe at least four times throughout the summer and determined that $50 \%$ of lambs from GPS-collared ewes survived until at least mid-summer, which is a typical survival rate (Geist 1971, Valdez \& Krausman 1999). Very little is known about the demography of this isolated, nonmigratory herd, so even though our sample size is small, gathering information on lamb survival and adult mortality is informative to managers in determining the need for a future demographic study or monitoring efforts. We will continue to collect lamb survival data during summers 2009 and 2010.

\section{Summer observations and movement}

Combined, field crews spent 95 days in the backcountry during summer 2008, tracking and observing bighorn sheep. We observed 229 bighorn sheep (many are repeat observations) on 42 different occasions (Fig. 4). The average group size observed was 5.5 individuals $(\min =1, \max =16)$. We completed six monitoring flights from June to August 2008 (Fig. 4). These flights assisted field crews in locating bighorn sheep groups with GPS-collars on the ground. Between monitoring flights and ground observations, we documented different movement tendencies between GPS-collared ewes. Movements ranged from $5 \mathrm{~km}$ throughout the summer, up to a maximum of $15 \mathrm{~km}$. Once we are able to collect the GPS-collars in July 2010 and download locations for each sheep, we will be able to gain a better understanding of the habitat selection strategies that influence these movement differences.

\section{Diet composition}

We observed bighorn sheep foraging most frequently on a variety of grasses, serviceberry (Amelanchier alnifolia), willow species (Salix spp.), arrow-leaved balsamroot (Balsamorhiza sagittata), columbine (Aquilegia flavescens), wild vetch (Vicia americana), and sticky geranium (Geranium viscosissimum). In summer 2008, we collected 62 bighorn sheep fecal samples. Eighteen $(29 \%)$ of the samples were collected fresh. We are currently awaiting diet composition results. We plan to continue our collection of fecal samples in summers 2009 and 2010.

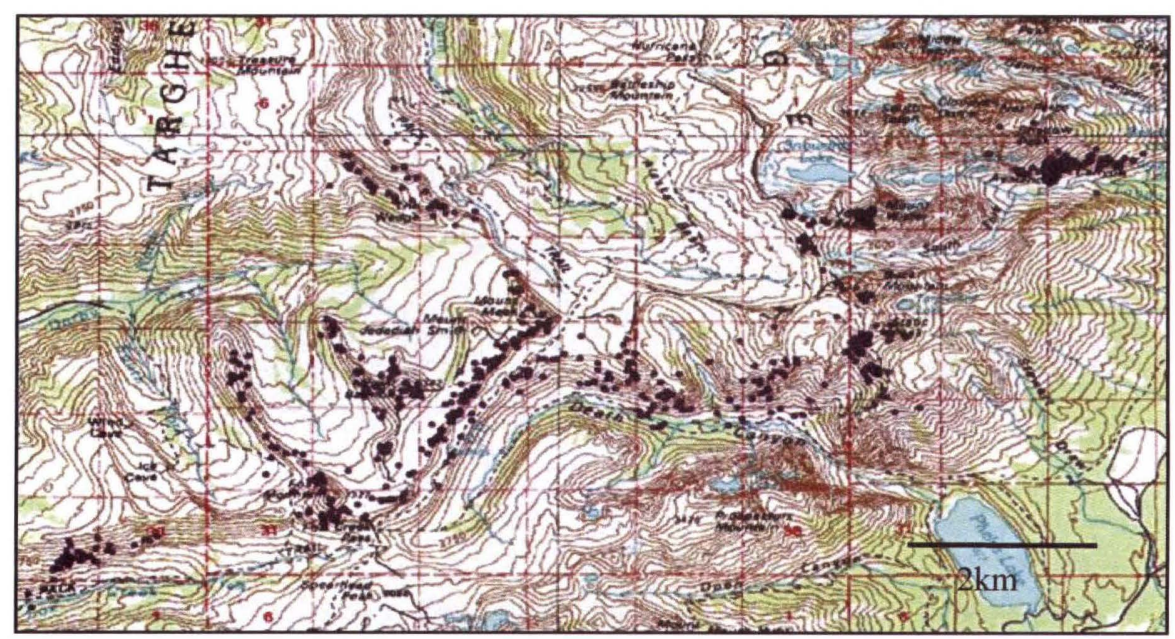

Figure 3. GPS location data downloaded from ewe 543. The GPS-collar was retrieved after the ewe died in an avalanche in December 2009, 10 months after capture. 


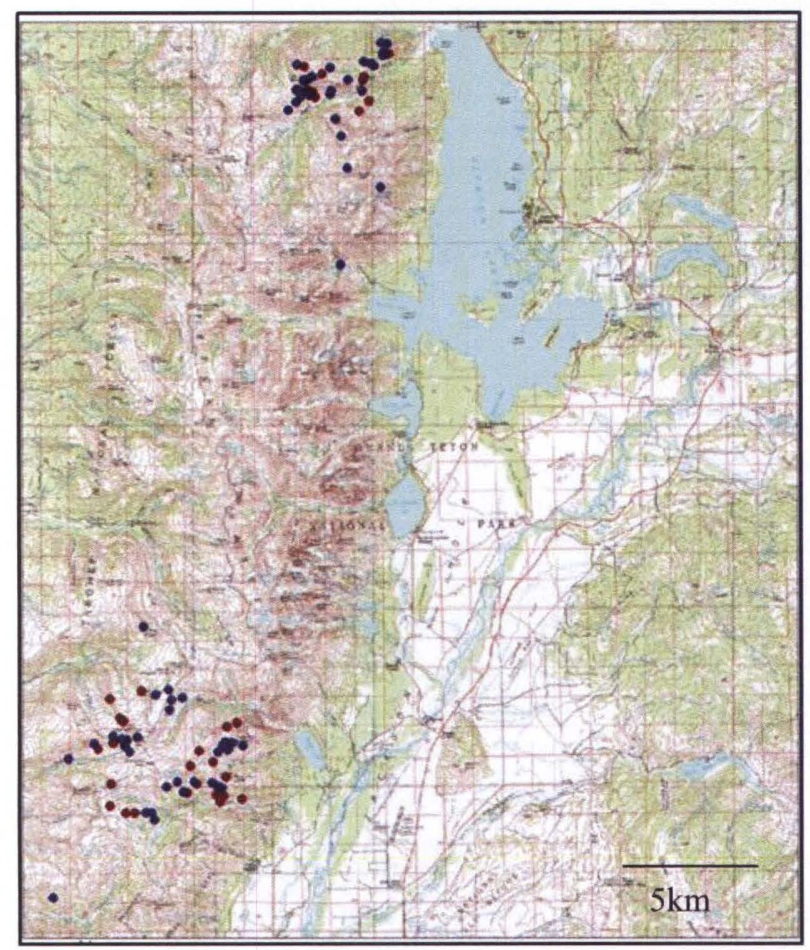

Figure 4. Aerial (red) and ground (blue) relocations of GPS-collared bighorn sheep, June - September 2008.

\section{Time-budgets}

During summer 2008, we completed timebudget observations on 53 individuals within 21 groups. Unfortunately, we had limited success in observing bighorn sheep groups foraging. Due to the challenging terrain in the Tetons and the difficulty of locating bighorn sheep groups, we often did not observe groups until mid-day, during which they were usually resting. During summers 2009 and 2010, we aim to increase our time-budget observations by altering our daily schedule and attempting to observe more bighorn sheep groups in the morning or late afternoon when they are more likely to be foraging.

\section{$\downarrow$ MANAGEMENT IMPLICATIONS}

The Teton Range bighorn sheep population has lost access to its historical winter range and migration patterns, which are threats facing many ungulate populations today. Results from this study will shed light on how this bighorn sheep population has adapted to wintering at high-elevations year-round and how the habitat selection strategies are different from migratory populations. This study will expand our understanding of the consequences of loss of migration for ungulate populations, the strategies that some may develop in order to persist, and the taxa and ecosystems that may more easily support non-migratory populations.

The results from this project will immediately contribute to decision-making by local wildlife managers at GTNP, BTNF, CTNF, and the WGFD and inform effective future bighorn sheep conservation and management strategies in the Teton Range. Knowledge of the population's habitat selection strategies and strategies to cope with living year-round on summer range will provide insight and justification to managers in future decision-making. This study will be completed in 2010 and results will be published in peerreviewed scientific literature and presented at various national and regional scientific conferences.

\section{ACKNOWLEDGEMENTS}

In addition to funding from the UW-NPS Research Station, this project is funded by the Wyoming Foundation for North American Wild Sheep (FNAWS), the Wyoming Governors Big Game License Coalition, Grand Teton National Park, the Rocky Mountain Cooperative Ecosystems Studies Unit, the Teton Conservation District, Bridger-Teton and Caribou-Targhee National Forests, the Eastern Chapter of FNAWS, and the Greater Yellowstone Coordination Committee. Design and coordination of the study has benefited from the work of Sarah Dewey, Steve Kilpatrick, and other members of the Teton Range Bighorn Sheep Working Group. At the University of Wyoming, we are thankful for the assistance of Steve Buskirk, Dan Doak, and Ken Gerow.

\section{$\uparrow \quad$ Literature Cited}

Berger, J. 1978. Group size, foraging, and antipredator ploys: an analysis of bighorn sheep decisions. Behavioral Ecology \& Sociobiology 4:91-99.

Bleich, V.C., J.D. Wehausen and S.A. Holl. 1990. Desert-dwelling mountain sheep: conservation implications of a naturally fragmented distribution. Conservation Biology. 4:383390.

Bolger, D.T., W.D. Newmark, T.A. Morrison and D.F. Doak. 2008. The need for integrative approaches to understand and conserve migratory ungulates. Ecology Letters 11:6377. 
Buechner, H.K. 1960. The bighorn sheep in the United States, its past, present, and future. Wildlife Monographs 4:3-174.

Frid, A. 1997. Vigilance by female Dall's sheep: interactions between predation risk factors. Animal Behavior 53:799-808.

Geist, V. 1971. Mountain sheep: a study in behavior and evolution. University of Chicago Press, Chicago, Illinois.

Hebert, D.M. 1973. Altitudinal migration as a factor in the nutrition of bighorn sheep. Ph.D. dissertation, University of British Columbia, Vancouver, Canada. 356 pp.

Hurley, K.P. 1996. History of transplanting mountain goats and mountain sheep - Wyoming. Proc. Biennial Symposium of the Northern Wild Sheep and Goat Council 10:205-209.

Klein, D.R. 1965. Ecology of deer range in Alaska. Ecological Monographs 35:259-284.

Lung, M.A. and M.J. Childress. 2006. The influence of conspecifics and predation risk on the vigilance of elk (Cervus elaphus) in Yellowstone National Park. Behavioral Ecology 18:12-20.

Newmark, W.D. 1996. Insularization of Tanzanian parks and the local extinction of large mammals. Conservation Biology 10:15491556.
Ottichilo, W.K., deLeeuw, J., and H.H.T. Prins. 2001. Population trends of resident wildebeest [Connochaetes taurinus hecki (Neumann)] and factors influencing them in the Masai Mara ecosystem, Kenya. Biological Conservation 97:271-282.

Risenhoover, K.L., J.A. Bailey and L.A. Wakelyn. 1988. Assessing the Rocky Mountain bighorn sheep management problem. Wildlife Society Bulletin 16:346-352.

Serneels, S. and E.R. Lambin. 2001. Impact of land-use changes on wildebeest migration in the northern part of the Serengeti-Mara ecosystem. Journal of Biogeography 28:391407.

Shackleton, D.M., C.C. Shank and B.M. Wikeem. 1999. Natural history of Rocky Mountain and California bighorn sheep. Pages 78-138 In: Mountain sheep of North America. R. Valdez and P.R. Krausman, (eds). The University of Arizona Press, Tucson, Arizona, USA.

Teton Range Bighorn Sheep Working Group. 1996. Strategic Plan for Managing Bighorn Sheep in the Teton Range. 24pp.

Valdez, R. and P.R. Krausman. 1999. Description, distribution, and abundance of mountain sheep in North America. Pages 3-22 In: Mountain sheep of North America. R. Valdez and P.R. Krausman, (eds.) The University of Arizona Press, Tucson, Arizona, USA.

Whitfield, M.B. 1983. Bighorn sheep history, distributions, and habitat relationships in the Teton Mountain Range, Wyoming. M.S. Thesis, Idaho State University, 244 pp. 